\title{
Hablo con mi cuerpo, y sin saber. Observaciones sobre el saber del cuerpo y el significante 123
}

\section{I speak with my body, without knowing. Remarks on the knowledge of the body and the signifier}

\section{Falo com meu corpo, e sem saber. Observações sobre o saber do corpo e o significante}

Luis Ernesto Behares (i)

\begin{abstract}
(i) Universidad de la República, Montevidéu, MVD, Uruguai. https:// orcid.org/0000-0002-6809-5128, lbeharesc@yahoo.com.

(ii) Universidad de la República, Montevidéu, MVD, Uruguai. https://orcid.org/0000-0001-9643-9314, raumar.isef@gmail.com, raumarr@fhuce.edu.uy.
\end{abstract}

Resumen: Este texto representa un avance en el perfilamiento teórico de la
posibilidad de hablar de un saber del cuerpo. En el desarrollo seguido con
afectación lacaniana, tienen lugar las siguientes preguntas: ¿Qué es el saber? ¿Qué
es, sobre todo, cuando se trata del sujeto o del ser hablante (parlêtre)? ¿Cómo aparece
el cuerpo cuando se trata del saber? Para trabajar sobre esas preguntas, el texto
presenta, en primer lugar, una discusión sobre el cuerpo, lo psíquico y el
conocimiento del mundo. Seguidamente, incluye consideraciones sobre el cuerpo
hablante y el saber del mundo, así como sobre la relación del saber del cuerpo con
el significante. Al final, se reflexiona teóricamente sobre la voz en tanto sonido de
un cuerpo para otro.
Palabras clave: cuerpo, saber, significante, voz

\footnotetext{
${ }^{1}$ Normalización bibliográfica: Aline Maya (Tikinet) - revisao@tikinet.com.br

2 Preparación y revisión de textos (español): Camila Pires de Campos Freitas camilacampos.revisora@gmail.com.

3 Editor responsable: Profa. Dra. Carmen Lúcia Soares - https://orcid.org/0000-0002-4347-1924, carmenls@unicamp.br
} 


\section{pro.posıções \\ $e$-ISSN 1980-6248}

http://dx.doi.org/10.1590/1980-6248-2018-0104

Abstract: This text represents an advancement in the theoretical shaping of the possibility of referring to the body's knowledge. In relation to the line of thought adhered to, which is affected by Lacanian ideas, the following questions arise: What is knowledge? What does the latter encompass when we are dealing with the subject or the speaking being (parlêtre)? How does the body appear when knowledge addressed? In order to elucidate these questions, this paper first deals with a discussion about the body, the psychic and knowledge about the world. Secondly, this paper includes considerations on the speaking body and knowledge about the world, as well as on the relationship between the body's knowledge and the signifier. Finally, there is a theoretical reflection on the voice considered as sound from a body towards another body.

Keywords: body, knowledge, signifier, voice.

Resumo: Este texto representa um avanço no perfilamento teórico da possibilidade de falar de um saber do corpo. No percurso desenvolvido com afetação lacaniana, têm lugar as seguintes perguntas: O que é o saber? O que é, sobretudo, quando se trata do sujeito ou do ser falante (parlêtre)? Como aparece o corpo quando se trata do saber? Para trabalhar nessas perguntas, o texto apresenta em primeiro lugar uma discussão sobre o corpo, o psíquico e o conbecimento do mundo, na sequência inclui considerações sobre o corpo falante e o saber do mundo, assim como sobre a relação do saber do corpo com o significante e, no final se reflete teoricamente sobre a voz. enquanto som de um corpo para outro.

Palavras-chave: corpo, saber, significante, vo\%:

\section{El cuerpo, lo psíquico y el conocimiento del mundo}

Este texto es un avance en el perfilado teórico de la posibilidad de hablar de un saber del cuerpo ${ }^{4}$. Se retoman algunos elementos formulados en trabajos anteriores de los autores y de otros investigadores que han aportado a estas discusiones en un marco de referencia afectado por el punto de vista lacaniano. Por lo tanto, las preguntas sobre las cuales se trabajará aquí son: ¿De qué se trata el saber? ¿De qué se trata, sobre todo, cuando hay un sujeto o incluso un parlêtre? ¿Cómo se pone en juego el cuerpo cuando se trata del saber? Una intervención de Lacan ha puesto parte de la cuestión en los siguientes términos:

¿Qué es el saber? Es extraño que antes de Descartes nunca se haya hecho la pregunta por el saber. Fue necesario el análisis para que se suscitara de nuevo.

\footnotetext{
${ }^{4}$ Este trabajo se inscribe en la línea de investigación "Cuerpo, educación y enseñanza”, del Instituto Superior de Educación Física (ISEF), Universidad de la República (Udelar), Montevideo, Uruguay.
} 


\section{pro.posıções \\ $e$-ISSN 1980-6248}

http://dx.doi.org/10.1590/1980-6248-2018-0104

$\mathrm{El}$ análisis vino a anunciarnos que hay saber que no se sabe, un saber que tiene su soporte en el significante como tal. (Lacan, 1975/1995, p. 116)

No es ninguna casualidad, sino más bien todo lo contrario, que, desde Descartes ${ }^{5}$, lo que no ha cesado de poner en jaque a la modernidad es la cuestión primera de la relación cuerpo-espíritu o cuerpo-alma, más tarde formulada como cuerpo-mente en el movimiento que sacó al cuerpo del discurso que se entiende como "filosofía” para colocarlo en el campo considerado como "científico", o por lo menos en el de ciertas formulaciones posibles para ciertas ciencias. Sin embargo, aunque no advertidos, hay en los científicos restos de "filosofía espontánea”, según la expresión de Althusser (1985). Si se acepta esa presencia residual, es preciso precaverse de las ideologías científicas, cuando lo que se intenta es hablar del saber, es decir: de aquello que sería, con pretensiones de precisión, de lo que se ocuparía la ciencia. La filosofía espontánea de los científicos, de acuerdo con Althusser (1985), remite a "las ideas ('conscientes' o no) que los científicos se hacen de la práctica científica de las ciencias y de 'la' ciencia" (p. 101). Esas ideas pueden calificarse de creencias o en la existencia real del objeto de conocimiento, o en la objetividad de los conocimientos de dicho objeto, o, en fin, en la corrección y eficacia del propio método aplicado. Pero también se vinculan a instancias externas a la práctica científica; por ejemplo, a lo que habitualmente llamamos "valores". Como la relación entre el elemento filosófico y el científico es inevitable, parece necesario mantener una atención crítica al respecto ${ }^{6}$.

Conviene, además, diferenciar con atención el uso que se le da a los términos "saber" y "verdad", que son necesariamente dos constructos diferentes, pero que, en los lindes entre filosofía y ciencia modernas, suelen parecer, a veces, recubriéndose el uno en el otro. Nada más concurrente a la confusión, si atendemos a los circuitos en los cuales ambos términos circulan, como lo ha explorado Rodríguez Giménez (2016, pp. 151-180). Si la verdad, desde el correspondentismo más elemental al más complejo, se alinea con el real posible, el saber lo hace con su imposibilidad, apresado en las redes del significante, por así decirlo. Pero esa verdad no deja, por más que lo reclamen los científicos, de estar inmersa en la imposibilidad simbólica:

\footnotetext{
5 Sin dudas, no solo con Descartes, porque también es necesario completar los efectos del racionalismo continental con lo que provino del empirismo británico.

6 Althusser (1985, pp. 119-158) analiza como pieza mostrativa un texto de Jacques Monod sobre la ciencia biológica moderna y el descubrimiento del ácido desoxirribonucleico (ADN), y reconoce en él marcas de la presencia de "filosofía espontánea" y de elementos de una cosmovisión.
} 


\section{pro.posıções \\ $e$-ISSN 1980-6248}

http://dx.doi.org/10.1590/1980-6248-2018-0104

se essa verdade toca um real, apenas é reconhecível por meio da linguagem, aí em sua função simbólica (não de significados, não de sentidos). Enquanto reconhecível por meio da linguagem, essa verdade escapa ao ser falante. Trata-se, desta maneira, de uma verdade em falta, ou do saber em falta de uma verdade. (Rodríguez Giménez, 2016, p. 135)

En la última cita de Lacan que reprodujimos, se enuncia la intrínseca relación del saber con la noción posible de sujeto en la tradición del "análisis". Conjuntamente, la cuestión del cuerpo, la problematización del cuerpo, su lugar en la estructura que da lugar a un sujeto, es algo que está en la base de toda la teorización freudiana y lacaniana. Por abstracta, inmaterial o etérea que pueda parecer, la "psique" no es sin cuerpo. Tener un cuerpo no es algo propio de cualquier viviente animal, es algo específico del hablante. Lo mismo se puede decir del hecho de tener un saber. Pero es porque se tiene un cuerpo que se puede tener un saber; la relación del hablante con el mundo no es sin cuerpo. Se advierte desde el principio que no se trata de un saber pleno, tampoco de la conciencia del mundo:

Sólo los cuerpos que hablan... tienen una idea del mundo como tal. El mundo, el mundo del ser pleno de saber, no es más que un sueño, un sueño del cuerpo en tanto que habla, porque no hay sujeto cognoscente. (Lacan, 1975/1995, p. 152)

La afirmación de que "no hay sujeto cognoscente" es uno de los postulados teóricos básicos para atender a los entramados de lo que adopta el nombre de "saber" en la teoría lacaniana. No lo hay tal y como lo ha propuesto la psicología, en sus múltiples variantes y formatos teóricos, que reproducen posturas filosóficas también variadas, a saber, un ente que deriva su condición de sujeto del conocimiento positivo del mundo, en su ámbito "psíquico" o "mental". Ese sujeto es, para toda y cualquier psicología, propietario de recursos cognitivos y de los resultados en el ejercicio de estos, o "conocimiento". Lo psíquico se presenta en las teorías psicológicas como "parejo" (no siempre idéntico, isomorfo o de pura correspondencia) con lo que efectiva y positivamente hay en el mundo exterior, por lo cual el lenguaje no es otra cosa para ese sujeto que un medio de expresión de sí, de producción de efectos en los semejantes y de representación del mundo ${ }^{7}$. En ese esquema, el cuerpo del sujeto cognoscente no es otra cosa que un organismo que sustenta o contiene los recursos cognitivos y las acciones implicadas en su puesta en uso.

\footnotetext{
${ }^{7}$ Estas tres posibilidades remiten a las tres funciones fenomenológicas tradicionales del lenguaje postuladas por Bühler (1934/1985), que las llamó sintomática o expresiva, señalativa o apelativa y simbólica o representativa. Sobre ellas se ha sustentado una filosofía del lenguaje muy resistente con anclaje en la teoría de la comunicación o en la "pragmática”-por ejemplo, en Jakobson (1960) y en Halliday (1978/1982).
} 


\section{pro.posições \\ $e$-ISSN 1980-6248}

Este entramado conceptualizador es opuesto a la teoría propuesta por Freud y Lacan; y con los cuidados explicitados por Lacan, se vuelve diametralmente opuesta, lo que pondría al campo psicoanalítico fuera del "campo psi”, si consideramos esa inclusión o esa exclusión estrictamente en el plano epistémico. El uso del término mismo, "psico-análisis", ideado por Freud y sustentado por la tradición internacional, presenta esa dificultad, y tal vez por eso Lacan evita el "psico-" y prefiere hablar simplemente de "análisis" en gran parte de su obra, como en el trecho que citamos en primer lugar.

\section{El cuerpo hablante y el saber del mundo}

Al cuerpo hablante (del ser hablante o parlêtre) le es completamente imposible el saber pleno del mundo y su representación plena, como puede sugerir la psicología, que Lacan (2005/2006) define como "imagen confusa":

Después de todo, la psicología no es otra cosa que la imagen confusa que tenemos de nuestro propio cuerpo. Pero esta imagen confusa implica afectos, para llamar a las cosas por su nombre. Si se imagina justamente esta relación psíquica, hay algo psíquico que se afecta, que reacciona, que no está separado... (p. 147).

El tener un cuerpo no es algo sin consecuencias. El individuo moderno dice tener un cuerpo. Si puede decirlo es porque está dividido: un alma o un espíritu y un cuerpo. Se trata de una operación metafísica que le permite al individuo decir "mi cuerpo", pero también de una operación económica: lo que piensa ("lo pensante", alma, espíritu o mente) se apropia del cuerpo, del cual derivará la posibilidad de un yo propietario de un cuerpo. Esta condición de "propietario" de un cuerpo, inherente a la mentalidad moderna, no es meramente asunto psicológico, ni se restringe a las formulaciones metafísicas más generales, sino que atraviesa los órdenes filosóficos, psicológicos, jurídicos, económicos y políticos, como ha logrado mostrar con detalle Seré Quintero (2017), texto al que remitimos por no estar en condiciones de resumirlo aquí con éxito.

De Descartes en adelante, la pregunta se impone: ¿Quién es ese que tiene un cuerpo, que lo posee? Luego, ¿qué significa allí “poseer”, sobre todo después de Locke? ¿Qué significa después de Marx? A los efectos de nuestra indagación, podemos decir que, en cualquier caso, para el parlêtre es algo que se tiene. Al respecto, dice Lacan (2005/2006): 


\section{pro.posıções \\ $e$-ISSN 1980-6248}

Relacionarse con el propio cuerpo como algo ajeno es ciertamente una posibilidad que expresa el uso del verbo tener. Uno tiene su cuerpo, no lo es en grado alguno. De aquí que se crea en el alma, después de lo cual no hay razones para detenerse, y también se piensa que se tiene un alma, lo que es el colmo. Pero la forma, en Joyce, del abandonar, del dejar caer la relación con el propio cuerpo resulta completamente sospechosa para un analista, porque la idea de sí mismo como cuerpo tiene su peso. Es precisamente lo que se llama el ego.

$\mathrm{Si}$ al ego se lo llama narcisista, es porque, en cierto nivel, hay algo que sostiene el cuerpo como imagen. (p. 147)

En esa relación que el parlêtre tiene con su cuerpo, en ese soportarlo como imagen, está la base y el fundamento de toda relación de conocimiento. Es el sócalo de toda relación con el mundo o, más precisamente, de toda relación imaginaria con el mundo, en la medida en que utilicemos el término "imaginario" exclusivamente en el sentido propio que se le asigna a este en la epistemología lacaniana del Real-Simbólico-Imaginario (RSI). Pero, entonces, ¿se trata solamente de una relación imaginaria? ¿'Todo lo que hay en esa relación es imaginario?

Es preciso que ustedes capten lo que les he dicho de la relación del hombre con su cuerpo, y que depende enteramente de que el hombre dice que él tiene el cuerpo, su cuerpo. Ya decir su es decir que lo posee, como un mueble, por supuesto. Esto no tiene nada que ver con lo que sea que permita definir estrictamente al sujeto, el cual solo se define de manera correcta por estar representado por un significante ante otro significante.

Aquí una observación que podría frenar un poquito lo que abisma en lo que podemos abarcar de la père-version por el uso del nudo borromeo. Nos sorprende completamente que haya algo donde el cuerpo ya no sirva como tal - es la danza. Esto permitiría escribir de manera algo distinta el término condanzación. (Lacan, 2005/2006, pp. 151-152)

La relación con el mundo, determinada en algún punto por la relación del ego con su cuerpo, no es solamente imaginaria. No puede serlo: si es imaginaria, lo es porque el viviente ya ha sido tomado en el campo del Otro, ya ha sido empujado, por así decirlo, al mundo de los hablantes. Allí donde tuvo lugar su enunciación como sujeto, allí debe hacerse un lugar para el enunciado, es decir, dar lugar a que opere el significante. Dividido como está, el parlêtre carga para siempre con un cuerpo, lo carga como una incógnita, como un enigma, por más extendidas y refinadas que estén las ciencias dedicadas a su estudio. Entonces, el parlêtre habla de su cuerpo, a la vez que habla con su cuerpo, sin saber.

$\mathrm{El}$ análisis se distingue entre todo lo producido con el discurso hasta entonces, por enunciar lo siguiente, hueso de mi enseñanza: que hablo sin saber. Hablo con mi cuerpo y sin saber. Luego, digo siempre más de lo que sé. (Lacan, 1975/1995, p. 144, nuestro énfasis) 


\section{pro-posıções \\ $e$-ISSN 1980-6248}

http://dx.doi.org/10.1590/1980-6248-2018-0104

En este "decir más de lo que sé", en ese resto que habla, es donde es posible dar otra dimensión al cuerpo, considerarlo como algo diferente a su representación imaginaria:

El hábito ama al monje, porque por eso no son más que uno. Dicho de otra manera, lo que hay bajo el hábito y que llamamos cuerpo, quizás no es más que ese resto que llamo objeto $a$.

Lo que hace que la imagen se mantenga es un resto. (Lacan, 1975/1995, p. 14)

La posibilidad del conocimiento o de una relación con el mundo, entonces, depende de un resto, lo cual puede ser entendido como una determinación inexorable. En el contexto del trabajo de Lacan del año 1975, en que se incluye el seminario sobre El Sinthome (Lacan, 2005/2006), el autor explora los efectos de la captura por la imagen del cuerpo en su Conferencia en Ginebra sobre el sintoma:

Pienso que el pensamiento es al fin de cuentas un enviscamiento ... Es un enviscamiento en algo que especifiqué con lo que llamo el imaginario y toda una tradición filosófica se percató de ello muy bien. Si el hombre -decirlo parece una banalidad - no tuviese lo que se llama un cuerpo, no voy a decir que no pensaría, pues esto es obvio, sino que no estaría profundamente capturado por la imagen de ese cuerpo.

El hombre está capturado por la imagen de su cuerpo. Este punto explica muchas cosas y, en primer término, el privilegio que tiene dicha imagen para él. Su mundo, si es que esta palabra tuviese algún sentido, su Unwelt, lo que lo rodea, él lo corpo-reifica, lo hace cosa e imagen de su cuerpo. (Lacan, 1988, p. 118) ${ }^{8}$

El "enviscamiento" se hace aparente, se constata, en que hay un decir, un discurso y unas prácticas; hace que parezca que el saber se asienta en un individuo, un ente preexistente a todo, y en la órbita del cual se sostienen tanto el conocimiento como el devenir de los hechos humanos. Cuando el individuo habla, parece que el saber es suyo, y eso es lo que lo autoriza a dar órdenes en nombre de lo que positivamente sabe. Pero, justamente porque absolutamente nada de eso se sostiene más que por las consistencias imaginarias (el “ego"), existen y permanecen las instituciones. Con buen tino, nos confiamos a la consistencia imaginaria, aunque no deberíamos hacerlo, finalmente, sin un poco de desconfianza. La consistencia imaginaria, característica en la composición de la civilización moderna, determina la visión de lo humano como una especie de "meta-individuo". En su concepto de "ego patrocinante", Behares (2014) lo ha analizado en estos términos:

\footnotetext{
${ }^{8}$ El término "enviscamiento" intenta traducir el original francés "engluement", que utilizó Lacan. Los dos hacen referencia al resultado de introducir algo en una substancia melosa o pegajosa. Tal vez, el término más extendido en su uso en español sea "embadurnamiento", ya que "enviscamiento" es de uso muy restringido.
} 


\section{pro.posıções \\ $e$-ISSN 1980-6248}

Por esta expresión queremos indicar una construcción conceptual e ideológica, el ego, que patrocina toda una visión de lo social y lo humano, en todos sus componentes (el pensamiento, la voluntad y el lenguaje incluidos), a partir de la estabilidad de los individuos, detentores de las claves necesarias a su propia justificación. En cierto sentido, podríamos también hablar de tautología egoica, que se postula desde un sí-mismo evidente y positivo. (p. 117)

El pensamiento moderno se sustenta, en gran medida, en este postulado de autonomía y consistencia positiva del individuo. Si este postulado no hubiera logrado consolidarse en la interpretación de las obras del hombre, en sus hechos, no tendría el poder patrocinante que se mencionó. Sin embargo, en la teoría que tiene por origen el psicoanálisis, se pone en entredicho esa autonomía y esa consistencia, y se permiten otras consideraciones. Como vimos, el hombre, en ella, está apresado entre su consistencia imaginaria y su (in)consistencia como cuerpo:

¿Qué es un hecho? Es justamente él quien lo hace. Solo hay hecho por el hecho de que el parlêtre lo diga. No hay otros hechos más que los que el parlêtre reconoce como tales diciéndolos. Solo hay hecho artificial. Y es un hecho que él miente, es decir, que instaura hechos, falsos y los reconoce porque tiene mentalidad, es decir amor propio.

$\mathrm{El}$ amor propio es el principio de la imaginación. El parlêtre adora su cuerpo porque cree que lo tiene. En realidad no lo tiene, pero su cuerpo es su única consistencia -consistencia mental, por supuesto, porque su cuerpo a cada rato le levanta campamento. Ya es bastante milagroso que subsista durante el tiempo de su consumación, que es de hecho, por el hecho de decirlo, inexorable. No hay nada que hacer, no es resoluble.

Ciertamente, el cuerpo no se evapora, y, en este sentido, es consistente. El hecho se constata incluso entre los animales. Cosa que resulta antipática a la mentalidad, porque esta cree tener un cuerpo para adorar. Esta es la raíz de lo Imaginario. (Lacan, 2005/2006, p. 64)

Lacan sustenta su planteamiento teórico en un cuerpo que adquiere su consistencia en el imaginario, pero que manifiesta constantemente su inconsistencia, en función de su condición de parlêtre, es decir de sujeto efecto del significante.

\section{Se sabe del cuerpo por el significante}

Por enigmático que sea el cuerpo para el ser hablante, algo indica su presencia. Las representaciones pueden ser muchas y diversas, por ejemplo: las que se asientan en cosmovisiones o tradiciones culturales varias, las que provee el campo de la ciencia o las que resultan de todo tipo de sincretismos. Cualesquiera que sean las representaciones, organizan el mundo, le dan consistencia imaginaria. Lo moderno se funda en la certeza de la existencia por 


\section{pro.posıções \\ $e$-ISSN 1980-6248}

http://dx.doi.org/10.1590/1980-6248-2018-0104

un "pienso" (cogito, je pense). Pero, “desde aquel pienso, que por suponerse a sí mismo, funda la existencia, hemos tenido que dar un paso, el del inconsciente" (Lacan, 1975/1995, p. 31). Desde entonces, la relación con el cuerpo está determinada por un saber en falta, por una falta de saber. No se trata de un saber que un día se iría a completar gracias al progreso de las ciencias; se trata de un saber cuya estructura responde a una incógnita, sin la cual no subsiste. El conocimiento del cuerpo, o mejor, las explicaciones de la relación del hablante con su cuerpo pueden proliferar y recubrir el mundo entero en varias capas, pero la falta de saber no cederá ni un milímetro.

El significante se asocia a efectos de significado, pero entre significante y significado hay una barrera (Lacan, 1975/1995, p. 27). El significante, en cuanto fundamento de lo simbólico, no conlleva ningún significado, más bien lo contrario, está allí para recordar la inconsistencia que lo imaginario tiende a olvidar.

No olvidemos que al comienzo se calificó, equivocadamente, de arbitraria la relación del significante y el significado. Así se expresa, probablemente a regañadientes, Saussure. Pensaba en algo muy distinto, y que está mucho más cerca del texto del Cratilo, como lo demuestra lo que hay en sus gavetas, a saber, las historias de anagramas. Ahora bien, lo que pasa por arbitrariedad es que los efectos de significado parecen no tener nada que ver con lo que los causa.

Pero es que, si parecen no tener nada que ver con lo que los causa, es porque se espera que lo que los causa tenga cierta relación con lo real. (Lacan, 1975/1995, pp. 28-29)

La referencia de Lacan a la opción u opciones de Saussure, si bien no podemos analizarla aquí en toda su magnitud, merece algunos comentarios mínimos. Las lecturas que se hicieron del (o de los) Cours de Saussure (1916) revelan cierta hesitación del lingüista y de sus intérpretes en cuanto a la "relación" entre el significante y el significado, que contiene la afirmación de la existencia de un vínculo entre uno y otro, entendido como arbitrario (o sea, opuesto a "motivado"), lo que solo se puede postular si se acepta que hay una relación substancial entre ellos. Sin embargo, se ha entendido también que la idea de "relación" es substituida en el pensamiento saussureano por la de "asociación", postulando un vínculo formal y efímero sin pretensiones substanciales ${ }^{9}$. Como sabemos, Lacan optó por interpretar a Saussure en este segundo sentido, y en la cita que introdujimos avanza en esa dirección, que

\footnotetext{
${ }^{9}$ Existe mucha controversia en la interpretación de lo que incluiría el texto de Saussure (1916) en cuanto a la relación o asociación entre significante y significado. Sobre ella, se puede ampliar en Milner (1978, 2002), Viltard (1995) y Behares (en prensa). Sobre lo que introduce Lacan de estas controversias, se puede consultar Le Gaufey (2010, pp. 123-140) y Fernández Caraballo (2008). Volveremos sobre esta cuestión más adelante.
} 


\section{pro.posıções \\ $e$-ISSN 1980-6248}

http://dx.doi.org/10.1590/1980-6248-2018-0104

había sido indicada ya en 1955, en el seminario Las psicosis (Lacan, 1981/1993, sobre todo pp. 229-354). El segundo párrafo de la cita quiere incluir, en el marco de su trilogía RSI, la afirmación de que los efectos de significado asociados al significante son la consistencia del imaginario, pero que el significante, si bien parece ser el causante de esos efectos, no está exento, materialmente, de relación con el real.

En el seminario Las psicosis (Lacan, 1981/1993, pp. 261-278), Lacan da forma a su discusión acerca del postulado "el significante, en cuanto tal, no significa nada". Con eso, no solo avienta la combustión empirista del significante como causa que se agota en la significación, su exclusividad en la tarea de significar, sino que le da la posibilidad de poner de manifiesto el descubrimiento freudiano de que "lo subjetivo no está del lado del que habla", sino que "lo subjetivo es algo que encontramos en lo real" (Lacan, 1981/1993, pp. 265-266). Aclara:

Sin duda lo real en juego no debe tomarse en el sentido en que lo entendemos habitualmente, que implica objetividad, confusión que se produce sin cesar en los escritos analíticos. Lo subjetivo aparece en lo real en tanto supone que tenemos enfrente un sujeto capaz de valerse del significante, del juego del significante. Y capaz de usarlo del mismo modo que nosotros lo usamos: no para significar algo, sino precisamente para engañar acerca de lo que ha de ser significado. Es utilizar el hecho de que el significante es algo diferente a la significación para presentar un significante engañoso. (Lacan, 1981/1993, p. 266).

Si el saber se confiesa, si adquiere la estabilidad del signo, imagen plena de significación, será llamado "conocimiento", pero ese saber insiste en faltar, en no ser completamente alojado en lo que llamamos conocimiento, continúa estando ahí, pero en su falta. Ese carácter en falta del saber hace que la relación con el cuerpo sea imperfecta en todos los seres humanos. Dice Lacan (2005/2006):

¿Quién sabe lo que pasa en su cuerpo? Hay en esto algo extraordinariamente sugestivo. Algunos incluso le dan este sentido al inconsciente. Sin embargo, si hay algo que desde el origen he articulado con cuidado, es que el inconsciente no tiene nada que ver con el hecho de que uno ignore montones de cosas respecto de su propio cuerpo. En relación con lo que se sabe, es de una naturaleza completamente distinta. Se saben cosas que dependen del significante. La antigua noción del inconsciente, lo Unerkannt, se apoyaba precisamente en nuestra ignorancia de lo que pasa en nuestro cuerpo.

El inconsciente de Freud es justamente la relación que hay entre un cuerpo que nos es ajeno y algo que forma círculo, hasta recta infinita, y que es el inconsciente, siendo estas dos cosas de todos modos equivalentes una a la otra. (pp. 146-147) 


\section{pro.posıções \\ $e$-ISSN 1980-6248}

http://dx.doi.org/10.1590/1980-6248-2018-0104

Si se sostiene la hipótesis del inconsciente, entonces, una de las primeras cosas que cae es esa idea que supone que a la mayor consciencia del cuerpo le corresponde una mayor libertad; pero resulta que no se sabe muy bien de qué se trata esa libertad. Es cierto que la idea de "pensar con el cuerpo", oriunda de Spinoza ${ }^{10}$, es provocadora, pero ¿qué quiere decir pensar con el cuerpo? O mejor, ¿quién es, finalmente, ese que piensa? $\mathrm{O}$, incluso, ¿qué es eso que piensa? "El sujeto no es el que piensa", dice Lacan (1975/1995):

Como hoy ando dándole vueltas a lo del inconsciente estructurado como un lenguaje, sépase: esta fórmula cambia totalmente la función del sujeto como existente. El sujeto no es el que piensa. El sujeto es propiamente aquel a quien comprometemos, no a decirlo todo, que es lo que le decimos para complacerlo -no se puede decir todo - sino a decir necedades [bêtises], ahí está el asunto. (p. 31)

La bêtise es la del significante, porque no se reconoce en ningún significado, remedando al sinsentido (nonsense) de la lógica estándar ${ }^{11}$. Y aquí, contrariamente a las filosofías de la conciencia (o "pseudo-filosofías"), se trata de no pensar o de aquello que tiene lugar en cuanto no es afectado por la existencia de un sujeto que no duda de su propia existencia. Eso habla (ça parle), pero habla en otro lugar y, aunque está estructurado como un lenguaje, según la fórmula lacaniana, no es algo que se inscriba sin más en el campo de las representaciones.

¿Qué es el saber del cuerpo? No se puede pretender saber del cuerpo del parlêtre como se sabe de una rata. El primero es un saber de los que hablan, el segundo de los que no hablan. Que el lenguaje sea la frontera en la cual se diferencia un cuerpo absoluto (animal) del cuerpo dicho es aceptado por la gran mayoría de los autores, aun sin aceptar los extremos lacanianos. Esto alcanza, por ejemplo, a Bourdieu. En El oficio de sociólogo (Bourdieu, Passeron, \&

\footnotetext{
${ }^{10}$ Si bien no podremos detenernos con parsimonia en la filosofía de Spinoza, dos componentes de ella nos parecen relevantes en el contexto de nuestra indagación: el monismo y, sobre todo, el materialismo. En su obra de 1677 (Ética demostrada según el orden geométrico), Spinoza (1677/2009) sostiene que sustancia pensante y sustancia extensa "son una sola y misma sustancia" (p. 134); las ideas tienen un orden inmanente e impersonal, de las cuales Dios es causa; la mens solo se provee de las imágenes que el cuerpo le provee. La expresión "pensar con el cuerpo", que en ocasiones es utilizada para contrastar con una tradición que privilegiaría el alma (también espíritu, mente, o simplemente razón), puede dar lugar a muchos equívocos. El principal: se puede ir por la vía de un materialismo vulgar que, finalmente, identifica al cuerpo con el organismo. Es evidente que entre Descartes y Spinoza hay diferencias importantes, pero la simple evocación del materialismo no resuelve el problema del dualismo. Por otra parte, hay que tener en cuenta los tres géneros de conocimiento presentes en la Ética de Spinoza (1677/2009): imaginación u opinión (primer género), razón (segundo género) y "ciencia intuitiva" (tercer género). Por último, también es pertinente recordar que, para Spinoza, el cuerpo no puede determinar al alma a pensar, así como los hombres no tienen poder sobre su lengua (cf. la sección Del origen y naturaleza de los afectos, en Spinoza, 1677/2009).

${ }^{11}$ Bêtise se puede traducir como tontería, majadería, futilidad, necedad, disparate, absurdo, sinsentido, etc., según los casos.
} 


\section{pro.posıções \\ $e$-ISSN 1980-6248}

http://dx.doi.org/10.1590/1980-6248-2018-0104

Chamboredon, 2002, p. 57), se dice que quizás la maldición de las ciencias sociales es la de tener un objeto que habla. Más allá del grado en que la sociología de Bourdieu pudo ser afectada por esta afirmación y por el discurso de Lacan, es evidente que la cuestión no le es ajena, como se observa en la obra citada.

Para Lacan, a lo largo de su extensa enseñanza, ese saber queda encriptado en la supremacía del significante respecto al sujeto. Sustantiva diferencia: sustancia gozante. "De la famosa sustancia extensa, complemento de la otra no podemos deshacernos así nomás, ya que es el espacio moderno" (Lacan, 1975/1995, p. 32). No sabemos qué es estar vivos sino por un cuerpo que se goza, dice Lacan, y ese cuerpo es algo distinto de la sustancia extensa. Se trata de una sustancia gozante, y es en ese nivel donde se sitúa el significante, más precisamente, "el significante es la causa del goce" (Lacan, 1975/1995, p. 33). No hay cuerpo sin significante. Y para no suponer que el organismo es lo real del cuerpo o una especie de realidad prediscursiva, hay que decir que tampoco hay organismo sin significante:

si el organismo es "lo vivo", el cuerpo adviene allí donde lo vivo es tomado en el campo del Otro, el momento en el que la dialéctica del significante hace su intervención allí donde sólo había la biología y su correlato en la necesidad (Rodríguez Giménez, en prensa, p. 5).

Pero, en fin, como se precisan palabras para orientarse, digamos que organismo es aquello viviente a lo cual se lo supone "lo sin deseo". Sin embargo, el deseo es algo de lo que ni siquiera el perro de Pavlov se liberó; el que manda es el significante.

La referencia a los experimentos de Pavlov tiene para Lacan la importancia de mostrar los límites de las relaciones que se articulan en su teorización entre el deseo, el significante y el cuerpo:

Lo reconozca o no Pavlov, la característica de toda condición experimental, en tanto que se instituye con el corte que puede hacerse en la organización orgánica de una necesidad, es, propiamente, asociar un significante - este corte se designa mediante una manifestación dentro de un ciclo de necesidades interrumpidas, y en la experiencia pavloviana resulta ser el corte del deseo... por eso, el animal no aprenderá jamás a hablar. Al menos por esa vía. Porque, evidentemente, tiene un tiempo de retraso. La experiencia puede provocar en él toda clase de desórdenes, pero al no ser hasta el presente un ser que habla, no está en condiciones de interrogar el deseo del experimentador. (Lacan, 1973/1993, p. 245)

Lacan había analizado la experiencia de Pavlov en 1967, en la primera clase de su seminario El acto psicoanalitico (Lacan, 1967-1968, pp. 5-15). Le importaba, principalmente, 


\section{pro-posições \\ $e$-ISSN 1980-6248}

http://dx.doi.org/10.1590/1980-6248-2018-0104

porque consideraba que el mérito atribuido a la teoría de Pavlov consistía en su recorte materialista de la coexistencia del organismo y de la conducta, potenciado en la ideología positivista del campo psi. Según Lacan, hay, en aquella experiencia, algo que es correcto, pero también ignorancia de sus presupuestos: el perro y Pavlov son diferentes, el toque de trompeta es signo-señal para el perro, pero es significante para Pavlov (o para cualquier experimentador que repitiera el experimento). Al mismo tiempo, la secreción salival es signo-señal, pero se torna significante al asociarse al primer significante y queda, por lo tanto, desligada del estímulo orgánico, cayendo en el rango de "efecto de engaño". Substituir la trompeta ${ }^{12}$ por una campana muestra a las claras este engaño, del que es víctima el organismo al ser tomado por el significante.

Si en los asuntos del saber del cuerpo todavía campea la herencia positivista, es porque la epistemología involucrada no se ha conmovido ante ese materialismo que dice "hay" (real), pero de lo cual no se puede saber nada sino por el significante (simbólico).

Hay tres suposiciones. La primera, o más bien la suposición uno, pues ya es excesivo darles un orden, es que, por arbitrario que sea, hay: proposición thética con no más contenido que su planteamiento mismo; gesto de corte sin el cual no hay nada que haya. Se nombrará esto real o R. Otra suposición, llamada simbólica o $\mathrm{S}$, es que hay lalengua, suposición sin la cual nada, y singularmente ninguna suposición, podría decirse. Otra suposición, por último, es que hay semejante, donde se instituye todo lo que forma lazo: es lo imaginario o I. (Milner, 1999, p. 9)

La famosa objetividad y neutralidad científica quieren suponer que describen lo real, pero sobra una palabra: describen. No se puede otra cosa que suponer lo real y, en todo caso, sostener ese supuesto hasta el final.

12 Lacan habla de "trompeta" cuando las referencias usuales hablan de "silbato": la diferencia no hace al experimento, así como si fuera una campana, o cualquier otro sonido, como fue posteriormente parte de los experimentos realizados. 


\section{pro.posıções \\ $e$-ISSN 1980-6248}

http://dx.doi.org/10.1590/1980-6248-2018-0104

\section{La voz: el sonido de un cuerpo para otro}

Las derivas en torno a la noción, o nociones, de significante que Saussure incluyó en sus cursos, y que hemos ya mencionado, pueden servir para mostrar una doble comprensión de su condición: el significante no puede ser desprendido totalmente del cuerpo, al cual pertenece por obviedad perceptible; y, por otro lado, el significante se le impone al cuerpo como una exterioridad absoluta en la que acabará siendo tomado o capturado. Esa aparente disyuntiva es tan antigua como la civilización occidental. Behares (2008, en prensa) ha mostrado que, para los antiguos, la vox (la foné de los griegos, el semáinon de los estoicos, el nomen o signans de los escolásticos) solo puede concebirse como lo que sale del cuerpo o como lo que entra en él. En ese sentido, lo interno y lo externo al cuerpo - lo que de la voz es del cuerpo, pero también la VOz como señal externa al cuerpo- entran en un juego que encontramos en Empédocles de Agrigento, Lucrecio, Crisipo de Solos, Agustín de Hipona y Tomás de Aquino, de donde vino a constituir tradición escolástica y pasó a la modernidad, sobre todo, en los empirismos que la habitan. Sin detenernos en consideraciones filológicas o arqueológicas, es justo reconocer que la pertenencia del significante al cuerpo, en tanto voz o cualquier otra cosa que el cuerpo pueda producir o percibir, es necesariamente persistente.

El corte producido por Saussure en sus cursos, señalado por diversos autores ya desde los años de 1940, consistió en la postulación de un argumento que, en la tradición de la lingüística, se entendió como "formalista", en oposición a "substancialista", según el cual el significante existe per se, separado de su caracterización psicofisiológica, referencialista y conceptualista. No obstante, la misma tradición ha entendido, con hesitaciones y mucha discusión, que existe una relación inmanente entre el significado y el significante, dando lugar a una teoría de la lengua como sistema de $\operatorname{signos}^{13}$. Un paso adelante, entendido como esencialmente saussureano, es el que da, con precisión, Milner (2002) al identificar que ese vínculo no es material, sino meramente accidental, por lo cual debería hablarse de asociación en lugar de relación. Según la línea de pensamiento que representó Milner, con ese movimiento, Saussure inauguró la posibilidad de concebir a la lengua como un orden autónomo y permitió pensar al significante como una operación cuya materialidad ya no se deriva de su carácter de señal ni de su condición de soporte a la significación y a la representación. Ese corte teórico

${ }^{13}$ El debate fue, en su momento, muy intenso, abarcó desde 1930 a 1970; y el volumen de bibliografía publicada es extensísimo. Citamos algunos clásicos: Bally (1940), Gardiner (1944), Coseriu (1954), Hjelmslev (1961), Engler (1962). 


\section{pro.posıções \\ $e$-ISSN 1980-6248}

http://dx.doi.org/10.1590/1980-6248-2018-0104

permitió algunos efectos inmediatos en la ciencia lingüística en sí misma. Si bien es cierto que sus construcciones teóricas pueden reconocer variados antecedentes (desde las antinomias platónico-aristotélicas, pasando por autores antiguos como Crisipo y Agustín, hasta los modernos, tanto en la tradición empirista como en la racionalista), Saussure ha innovado y permitido potenciar la consideración del significante que resultó imprescindible para que Lacan hiciera luego su intervención sobre la cuestión de la pulsión freudiana.

Se ha señalado que, en la obra de Freud, la teoría de la pulsión hace centro para dar cuenta de la cuestión del saber en el pensamiento psicoanalítico. La expresión ontogenetista “orígenes pulsionales del saber", acuñada por Lemérer (1999) en su interpretación del texto de Freud sobre las "teorías sexuales infantiles" (Freud, 1908/2003), ha instalado la posibilidad de relacionar pulsión y saber en términos teóricos, rectificando (con asiento en la visión lacaniana) las tradicionales desviaciones psicologistas que revierten el psicoanálisis al asociacionismo en el cual se separan ambas "funciones" (cognitiva y emocional). Lemérer rescató del texto freudiano de 1908 el término Wissbegierde (usado en la expresión sexual Wissbegierde), de escasa valoración en el discurso psicoanalítico (traducido indiferentemente como "curiosidad intelectual", "avidez de saber" o "deseo de saber"). La autora vincula la "curiosidad" infantil frente a lo sexual y a los cuerpos con la "investigación", entendida como labor intelectual, actividades teóricas o acciones de tipo epistémico. Jerarquiza la frase de Freud, "en la manera genial de un teórico" (Lemérer, 1999, p. 13), que él constituyó para explicar que el niño se enfrenta a la vez a las "urgencias de la vida", a las necesidades egoístas de su pulsión, a su Lebensnot, y a las respuestas insuficientes e inhibitorias provenientes del mundo adulto. La instauración del Wissbegierdeno podría darse, según él, sin estas dos tensiones conjugadas. Es más: para Freud (1908/2003) está allí el origen de la escisión psíquica. Por un lado, "una de las opiniones, la que conlleva el ser bueno, pero también la suspensión del reflexionar, deviene la dominante, consciente" (p. 191). Por otro, la investigación infantil y sus resultados, "que no deben tener vigencia", devienen sofocadas, "inconscientes".

No es muy común, aun en el campo psicoanalítico, que se oiga hablar de una verdadera y consistente “epistemología freudiana”. Si, como sostiene Lemérer, esta es posible, lo es porque en su principio está la pulsión. La pulsión no es una mera expresión natural de los cuerpos, un impulso de saber (Wissendrang) biológico automático, sino el efecto de la escisión psíquica. Existen construcciones consagradas en el mundo humano externo a los individuos que estos reciben hechas y estabilizadas; y hay formaciones alternativas a ellas, insurrectas y 


\section{pro.posições \\ $e$-ISSN 1980-6248}

delirantes. No es nada insólito llamar a las primeras conocimiento y a las segundas saber. Freud (1908/2003), al discurrir acerca de las falsas teorías sexuales infantiles, sostiene que, aunque ellas sean "grotescamente falsas, cada una de ellas contiene un fragmento de verdad" (p. 192) y afirma que son análogas a la investigación científica. Ambas se explican, según él, por los componentes de la pulsión sexual, y no son explicables por la repetición consciente de verdades ya confirmadas y estabilizadas, sino todo lo contrario. Hay en ellas "fragmentos de verdad", es decir, instanciaciones que dan forma a la dimensión propia del saber. El conocimiento es arte del goce, mientras que el saber lo es de la falta.

Freud utilizó el término pulsión (alemán Trieb) por primera vez en 1905, en sus ensayos sobre la teoría sexual (Freud, 1905/2003), con un fuerte comprometimiento con las representaciones energéticas. A esa etapa parece corresponder, en forma más o menos ajustada, a la definición de Roudinesco y Plon (2005): “carga energética que está en la fuente de la actividad motriz del organismo y del funcionamiento psíquico del inconsciente humano" (p. 883). A pesar de ese origen, la noción de pulsión freudiana presentó, desde el principio, la postulación de su carácter desplaz̧ado, rasgo que, en textos posteriores, se presenta como esencial y definitorio. El desplazamiento se explica básicamente porque la pulsión, a diferencia del instinto, no concurre ni puede concurrir plenamente a su satisfacción, en tanto se vincula con la represión:

Por "pulsión" podemos entender al comienzo nada más que la agencia representante (Repräsentanz) psíquica de una fuente de estímulos intrasomática en continuo fluir; ello a diferencia del "estímulo", que es producido por excitaciones singulares provenientes de afuera. Así, "pulsión" es uno de los conceptos del deslinde de lo anímico respecto de lo corporal.(Freud, 1905/2003, p. 153)

Diez años más tarde, al reanalizar su concepto inicial de pulsión, Freud agregó:

Si ahora desde el aspecto biológico pasamos a la consideración de la vida anímica, la "pulsión" nos aparece como un concepto fronterizo entre lo anímico y lo somático, como un representante (Repräsentanz) psíquico de los estímulos que provienen del interior del cuerpo y alcanzan el alma, como una medida de la exigencia de trabajo que es impuesta a lo anímico en su trabazón con lo corporal. (Freud, 1915/2003b, p. 117)

Ese carácter "fronterizo", de "deslinde", vinculado a la "escisión psíquica", que Freud postuló como evidencia en su trabajo inicial sobre el concepto de pulsión, trae aparejada la dificultad de incluirlo como un componente de la teoría psicoanalítica. La dimensión "fronteriza" de la pulsión implicó, para muchos psicoanalistas, la opción de la predominancia 


\section{pro.posıções \\ $e$-ISSN 1980-6248}

http://dx.doi.org/10.1590/1980-6248-2018-0104

de la dimensión biológica por sobre la dimensión psíquica: un testimonio de esta tendencia estuvo presente en la elección de las palabras con que se ha intentado traducir el término alemán Trieb freudiano, de lo cual nos informan Roudinesco y Plon (2005, p. 883), y Laplanche y Pontalis (1979, p. 335).

En diversos pasajes de su obra, que Strachey (2003, p. 109) pormenorizó, Freud había manifestado repetidamente que el concepto de pulsión presentaba todavía puntos de oscuridad en la teoría psicoanalítica, aunque se la presentaba como el pilar de su teorización. Se refiere, en aquellos años tempranos del siglo XX, a su propia obra, y tal vez a poco más que ella; no obstante, es posible afirmar que las oscuridades de la conceptualización de la pulsión están al orden del día en la bibliografía posterior, sobre todo cuando se intenta seguir la pista de una relación epistémica con una potencial aproximación a las cuestiones del saber. Un factor en ese entramado había quedado diluido hasta las intervenciones lacanianas: la escritura de la pulsión freudiana no puede substraerse al lenguaje. Al incluir en su tratamiento de ella los conceptos de representación-representante, Freud introdujo un aporte determinante a la diferenciación entre lo anímico y lo orgánico, que veremos más tarde potenciado en los desarrollos lacanianos.

$\mathrm{Al}$ analizar el itinerario de la postulación de la noción de pulsión en diversos textos de Freud, Behares (2007) ha logrado establecer algunos parámetros acerca de la vital necesidad de pensar la cuestión del lenguaje como inherente a esas consideraciones, que resumimos brevemente a continuación. Ya en su texto de 1915, Pulsiones y destino de pulsión, Freud (1915/2003b) remite a las formas del lenguaje para dar cuenta de los desplazamientos pulsionales a que hace referencia. En este y en otros textos (Freud, 1900/2004, 1901/2004, 1905/2004), Freud se enfrenta a los equívocos y a los desplazamientos que reconocemos como de orden lingüístico vinculados a la pulsión, y en algunos argumentos parece estar cerca de darles una jerarquía definida. Sin embargo, no formula la afirmación de que la pulsión es intrínsecamente del orden del lenguaje. En esa misma dirección, parece estar la caracterización freudiana de los conceptos técnicos de representación (Vorstellung), con sus distinciones entre representación de cosa y de palabra (Sachvorstellung, Wortvorstellung), de representante (Repräsentantz) y de otros que integran esa serie. Se pregunta Behares (2007):

¿Qué de lo que concebimos como lenguaje está siempre implicado en la tradicional Vorstellung de la filosofía alemana incorporada por Freud? ¿Cuánto de lo que Freud bautizó como "pulsión" sólo puede inscribirse en la dimensión equívoca propia del lenguaje? Se puede decir, 


\section{pro.posıções \\ $e$-ISSN 1980-6248}

con algo de vaguedad, es cierto, que en la obra de Freud la conceptualización del lenguaje es "precaria", o para ser menos duros, "indefinida". A veces da la impresión de una conceptualización "intelectualista", al atribuir al lenguaje todas y sólo las propiedades del fenómeno consciente, otras se presenta como marcadamente "instrumentalista", reduciéndolo sólo a un mecanismo de intercambio, y, en otras casi cae en los límites del concepto de "hábito"... No obstante, conviene no ser tan taxativos con el vienés: en algunos de sus desarrollos teóricos introduce una visión diferente a aquéllas, a saber la que se vincula a las dimensiones propias de la estabilidad representacional en oposición a la inestabilidad inherente a un medio estructurante "convencional". (pp. 11-12)

En su mayoría, las observaciones que Freud introduce en los textos que hemos mencionado señalan la inestabilidad y contingencia de los dichos de sus pacientes y remiten a la tradicional consideración de los lapsus linguae, reconocidos desde antiguo como parte de las particularidades del signo lingǘstico ${ }^{14}$. En su tratamiento de la Vorstellung (representación), Freud da espacio a la inconsistencia de la significación. En su abordaje, la representación está presentada, en primer lugar, como las composiciones eidéticas conscientes y, en segundo, como las "huellas mnémicas" (cualitativas) inconscientes. En ambos casos, la representación se opone al "afecto" (Affekt), constituido por las descargas cuantitativas de tipo pulsional. Por tanto, la representación corresponde al significado (o al signo estabilizado) y es fenómeno de la consciencia, pero también al significante desligado de esa estabilización, y allí es fenómeno del empuje pulsional propio del inconsciente. Pero, más allá de la representación, Freud reconoce espacio para la descarga corporal propia de la pulsión, que no se inscribe como inconsciente. Reconoció que algo del orden pulsional está siendo reprimido y que arrastra representaciones que fueron conscientes y pasan al inconsciente, como lo expresa en 1915:

El destino general de la representación representante de la pulsión difícilmente pueda ser otro que este: desaparecer de lo consciente si antes fue consciente, o seguir coartada de la consciencia si estaba en vías de devenir consciente... El factor cuantitativo de la agencia representante de pulsión tiene tres destinos posibles, como nos lo enseña una ojeada panorámica a las experiencias que nos ha brindado el psicoanálisis: La pulsión es sofocada por completo, de suerte que nada se descubre de ella, o sale a la luz como un afecto coloreado cualitativamente de algún modo, o se muda en angustia. (Freud, 1915/2003a, pp. 147-148)

Para Freud, por lo tanto, existe una dimensión de la pulsión que no puede concebirse sin la composición representativa propia del lenguaje, aunque no se inscriba en la estabilidad del signo, que se corresponde con el inconsciente. Freud dice que es de tipo "cualitativo",

\footnotetext{
${ }^{14}$ Desde Agustín de Hipona (1873), que se percataba de que "sin quererlo nosotros, brotan de la lengua unas palabras por otras, pues tampoco aquí las palabras se oyen como signos de las cosas que tenemos en el ánimo" (p. 282, nuestra traducción).
} 


\section{pro.posições \\ $e$-ISSN 1980-6248}

caracterización que remite en su obra a la oposición cualitativo-cuantitativo, en clara sujeción al principio biológico de "energía" pulsional. Pero, además, existe otra dimensión en el pensamiento freudiano, de tipo ahora "cuantitativo", que se sustrae a la representación, y que Freud llama "afecto", en la que la cuestión pulsional parece excluirse de los efectos del lenguaje. Leite (2006), siguiendo a Lacan en el Seminario La angustia (Lacan, 2004/2006), llama la atención sobre la afirmación de que la angustia es el único afecto, el que no engaña, si se parte de una definición de afecto como el efecto irreductible del significante sobre el cuerpo:

Retomando o que Freud elaborou no texto de 1915 intitulado "O recalque", Lacan afirmará que o afeto está desarrimado, vai à deriva; podemos encontrá-lo deslocado, louco, invertido, metabolizado, mas não recalcado, ele insiste. É sobre os significantes que o amarram que incide o recalcamento. Os afetos assim produzidos irão deslocar-se ao longo da cadeia de significantes, e deste modo só podem se distanciar de seu lugar de origem. Constituem-se necessariamente como enganadores; reside aí a falta de valor epistêmico a eles atribuída. (Leite,2006, p. 120)

\section{Consideraciones finales}

Sin transgredir las limitaciones de toda estabilización, y con el pudor analítico imprescindible, podemos concluir algunas afirmaciones. Es posible decir de un cuerpo que se sostiene en su apelación a un real anterior a toda práctica significante (el organismo, la machina), el cuerpo de la ciencia empírica y correspondentista, que se basa en la verdad de sus enunciados como una vuelta incansable a la naturaleza. Ese es el cuerpo que es posible también para la psicología, en la medida en que esta no se aventura a ver más allá de la consciencia y de su entramado imaginario.

Pero es obvio que, igualmente, el cuerpo vuelve como expresión del corte significante, porque el sujeto queda constituido a causa de ese corte como aquel que habla su deseo. Entonces, de lo que se trata es del cuerpo hablante del ser hablante o parlêtre, que habla con su cuerpo, porque la vOz es cuerpo, pero también porque el cuerpo no es sin significantes. Recordemos los comentarios de Lacan:

[Los filósofos ingleses] No piensan que las pulsiones son el eco en el cuerpo del hecho de que hay un decir.

Para que resuene este decir, para que consuene, otro término del sinthomemadaquin, es preciso que el cuerpo sea sensible a ello. De hecho lo es. Es que el cuerpo tiene algunos orificios, entre los cuales el más importante es la oreja, porque no puede taponarse, clausurarse. Por esta vía responde en el cuerpo lo que he llamado la voz. 


\section{pro.posições \\ $e$-ISSN 1980-6248}

http://dx.doi.org/10.1590/1980-6248-2018-0104

Lo molesto, por cierto, es que no está solo la oreja, y que la mirada compite notablemente con ella.

More geométrico, a causa de la forma, cara a Platón, el individuo se presenta como puede, como un cuerpo. Y este cuerpo tiene un poder tan cautivante que hasta cierto punto habría que envidiar a los ciegos. (Lacan, 2005/2006, p. 18)

El goce del cuerpo es el espacio en el que el deseo del cuerpo mal parece satisfacerse. Se podría preguntar si ese goce, que Lacan asoció al sinthomemadaquin ${ }^{15}$, sería otra forma de "la propiedad del cuerpo" o de la "tenencia del cuerpo" y de un saber del cuerpo que allí estuviera contenido. Al final, del saber del cuerpo ¿se puede hacer algo más que gozar de una falta? No obstante, recordemos el Afekt, en el que se manifestaría otro cuerpo que el representado o que el que falta al decirlo. Sin muchas aprensiones, podríamos afirmar que sobre ese cuerpo quiso pensar Lacan en los últimos Seminarios que dictó, sobre lo cual, por ahora, haremos mutis por el foro.

\section{Referencias}

Agustín de Hipona. (1873). De magistro. In EEuvres complètes de Saint Augustin évêque d'Hippone (Tomo 3, p. 254-291). Paris: Librairie de Louis Vivès.

Althusser, L. (1985). Curso de filosofía para científicos. Barcelona: Planeta-Agostini.

Bally, C. (1940). L’arbitraire du signe: Valeur et signification. Le Français moderne, 8, 193-206.

Behares, L. E. (2007). Enseñar en cuerpo y alma: La teoría de la enseñanza y el saber en la pulsión. ETD: Educação Temática Digital, 8, 1-21. Recuperado de https://periodicos.sbu.unicamp.br/ojs/index.php/etd/article/view/688

Behares, L. E. (2008).De un cuerpo que responda a la palabra: Un retorno a la "teoría antigua" de la enseñanza. In L. E. Behares \& R. Rodríguez Giménez (Comps.), Cuerpo, lenguaje y enseñanza (pp. 29-46). Montevideo: Universidad de la República.

\footnotetext{
15 Un doble juego de palabras por homofonía, introducido por Lacan, en referencia al sainthomme (Sinthome) y a Saint Thomas d'Aquin (sinthomadaquin), en el seminario El sinthome (Lacan, 2005/2006, pp. 14-15), para reconocer el origen filosófico-teológico de la noción de "síntoma" que elabora, y utiliza una forma arcaica en francés (sinthome, en lugar del francés contemporáneo symptôme) para alejarse de la noción de síntoma de la medicina.
} 


\section{pro.posıções \\ $e$-ISSN 1980-6248}

Behares, L. E. (2014). Ego patrocinante y políticas educativas. In D. P. V. Bolzan (Org.), VI Encontro Internacional de Investigadores de Políticas Educativas (pp. 113-122).Santa María: UFSM-AUGM.

Behares, L. E. (en prensa). El significante, después y antes de Saussure: Notas para una historia del concepto. In C. Blezio Ducret (Dir.), Lejos de preceder al punto de vista: Lecturas lenguajeras sobre Ferdinand de Saussure. Montevideo: Biblioteca Plural/CSIC/Udelar.

Bourdieu, P., Passeron, J.-C., \& Chamboredon, J.-C. (2002). El oficio de sociólogo: Presupuestos epistemológicos. Buenos Aires: Siglo XXI.

Bühler, K. (1985). Teoría del lenguaje. Madrid: Alianza Editorial. (Trabajo original publicado en 1934)

Coseriu, E. (1954). Forma y sustancia en los sonidos del lenguaje. Montevideo: Facultad de Humanidades y Ciencias.

Engler, R. (1962). Théorie et critique d'un principe saussurien: L'arbitraire du signe. Cabiers Ferdinand de Saussure, 19, 5-16.

Fernández Caraballo, A. M. (2008). Qué de Lacan es saussureano? Algunas precisiones y desmitificaciones. Cadernos de Estudos Lingüisticos, 52(1), 23-35.

Freud, S. (2003). Tres ensayos de teoría sexual. In J. Strachey (Comp.), Sigmund Freud: Obras completas (Tomo 7, pp. 109-222). Buenos Aires: Amorrortu Editores. (Trabajo original publicado en 1905)

Freud, S.(2003). Sobre las teorías sexuales infantiles. In J. Strachey (Comp.), Sigmund Freud: Obras completas (2a ed., Tomo 9, pp. 183-200). Buenos Aires: Amorrortu Editores. (Trabajo original publicado en 1908)

Freud, S. (2003a).La represión. In J. Strachey (Comp.), Sigmund Freud: Obras completas (2a ed., Tomo 14, pp. 135-152). Buenos Aires: Amorrortu Editores. (Trabajo original publicado en 1915).

Freud, S. (2003b). Pulsiones y destinos de pulsión. In J. Strachey (Comp.), Sigmund Freud: Obras completas (2a ed., Tomo 14, pp. 105-139).Buenos Aires: Amorrortu Editores. (Trabajo original publicado en 1915) 


\section{pro.posições \\ $e$-ISSN 1980-6248}

Freud, S. (2004). La interpretación de los sueños. In J. Strachey (Comp.), Sigmund Freud: Obras completas (Tomo 4). Buenos Aires: Amorrortu Editores. (Trabajo original publicado en 1900)

Freud, S. (2004). Psicopatología de la vida cotidiana. In J. Strachey (Comp.), Sigmund Freud: Obras completas (2a ed., Tomo 6). Buenos Aires: Amorrortu Editores. (Trabajo original publicado en1901)

Freud, S. (2004).El chiste y su relación con el inconsciente. In J. Strachey (Comp.). Sigmund Freud: Obras completas (2a ed., Tomo 8). Buenos Aires: Amorrortu Editores. (Trabajo original publicado en 1905)

Gardiner, A. H. (1944).De Saussure's analysis of the "signe linguistique". Acta Lingüistica, 4(1), 107-110.

Halliday, M. A. K. (1982). El lenguaje como semiótica social: La interpretación social del lenguaje y del significado. México: Fondo de Cultura Económica. (Trabajo original publicado en 1978)

Hjelmslev, L. (1961). Prolegomena to a theory of language (F. Witfield, trad.). Madison: The University of Wisconsin Press. (Trabajo original publicado en 1943)

Jakobson, R. (1960). Closing statements: Linguistics and poetics. In T. A. Sebeok (Ed.), Style in language (pp. 350-377). Cambridge: MIT Press.

Lacan, J. (1967-1968). El acto psicoanalitico, 1967-1968.

Lacan, J. (1988). Conferencia en Ginebra sobre el síntoma. In Intervenciones y textos 2 (pp. 115144). Buenos Aires: Manantial.

Lacan, J. (1993). El seminario de Jacques Lacan, libro 3: Las psicosis, 1955-1956(J. L. D. Mauri \&D.S. Rabinovich, trads.). Buenos Aires: Paidós. (Trabajo original publicado en 1981)

Lacan, J. (1993). El seminario de Jacques Lacan, libro 11: Los cuatro conceptos fundamentales del psicoanálisis, 1964(J. L. D. Mauri \& J. Sucre, trads.). Buenos Aires: Paidós. (Trabajo original publicado en 1973)

Lacan, J. (1995). El seminario de Jacques Lacan, libro 20: Aun, 1972-1973(D. Rabinovich, J. L. D. Mauri \& J. Sucre, trads.). Buenos Aires: Paidós. (Trabajo original publicado en 1975)

Lacan, J. (2006). El seminario de Jacques Lacan, libro 23: El sinthome, 1975-1976(N. A. González, trad.). Buenos Aires: Paidós. (Trabajo original publicado en 2005) 


\section{pro.posıções \\ $e$-ISSN 1980-6248}

http://dx.doi.org/10.1590/1980-6248-2018-0104

Lacan. J. (2006). El seminario de Jacques Lacan, libro 10: La angustia, 1962-1963(E. Berenguer, trad.). Buenos Aires: Paidós. (Trabajo original publicado en 2004)

Laplanche, J., \& Pontalis, J. B. (1979). Diccionario de psicoanálisis (2a ed.). Barcelona: Editorial Labro.

Le Gaufey, G. (2010). El sujeto según Lacan (M.A. Castagnola \& A. Arcos, trads.). Buenos Aires: Ediciones Literales-El Cuenco de Plata.

Leite, N. (2006). Da obra ao ato: Quando o simbólico fracassa.In N. Leite (Org.), Corpolinguagem: Angústia: O afeto que não engana (pp. 117-124). Campinas: Mercado de Letras.

Lemérer, B. (1999). Algumas reflexões a partir do texto de Freud sobre as teorias sexuais infantis. Letra Freudiana, 17(23), 13-20.

Milner, J.-C. (1978). L'Amour de la langue. Paris: Du Seuil.

Milner, J.-C. (1999). Los nombres indistintos. Buenos Aires: Manantial.

Milner, J.-C. (2002). Le periple estructurale: Figures et paradigmes. Paris: Du Seuil.

Roudinesco, E.,\&Plon, M. (2005). Diccionario de psicoanálisis. Buenos Aires: Paidós.

Rodríguez Giménez, R. (2016). Saber do corpo: Entre o político e a política. Tese de Doutorado, Universidade Federal de Santa Catarina, Florianópolis.

Rodríguez Giménez, R. (en prensa). Consideraciones sobre la distinción entre cuerpo y organismo a propósito de la relación entre vida y política.

Saussure, F. (1916). Cours de linguistique generale. Payot: Paris.

Seré Quintero, C. (2017). Propriedade do corpo: Sujeito, direito e trabalho. Tese de Doutorado, Universidade Federal de Santa Catarina, Florianópolis.

Spinoza, B. (2009). Ética demostrada según el orden geométrico. Madrid: Tecnos. (Trabajo original publicado en 1677)

Strachey, J. (2003). Introducción a "Pulsiones y destinos de pulsión”. In J. Strachey (Comp.), Sigmund Freud: Obras completas (2a ed., Tomo14, pp. 107-112). Buenos Aires: Amorrortu Editores. 


\section{pro.posıções \\ $e$-ISSN 1980-6248}

Viltard, M. (1995). Hablar a los muros: Observaciones sobre la materialidad del Signo. Litoral, 18/19, 51-95.

Informaciones de sumisión: Sometido a evaluación el 8 de septiembre de 2018; acepto para publicación el 22 de octubre de 2018.

Autor correspondiente: Raumar Rodríguez Giménez: Universidad de la República - Instituto de Educación, Avenida Uruguay 1695 Montevideo 11200, Uruguay 